\title{
Chemical and biological control of Fusarium species involved in garlic dry rot at early crop stages
}

\author{
Letizia Mondani • Giorgio Chiusa • Paola Battilani (D
}

Accepted: 10 March 2021 / Published online: 26 March 2021

(C) The Author(s) 2021

\begin{abstract}
The aim of the study was to test in vitro and in vivo the efficacy of triazoles and biocontrol agents (BCAs) against Fusarium proliferatum and $F$. oxysporum, the former signaled as the main causal agent of garlic dry rot and the latter also involved. In vitro trials were organized using potato dextrose agar with added chemicals or BCAs inoculated with selected $F$. proliferatum and F. oxysporum. Garlic cloves were dipped before sowing in suspensions prepared with the fungicides showing the best performances in vitro; then they were dipped in Fusaria suspension before sowing. In in vitro trials, the maximum Fusaria growth inhibition was performed by Propiconazole + Prochloraz (100\%), followed by Tebuconazole (88.9\%). BCAs showed great capacity to control Fusaria, with a maximum growth inhibition of $80 \%$ (Trichoderma harzianum $+T$. gamsii). In vivo bacterial BCAs showed a similar capacity to
\end{abstract}

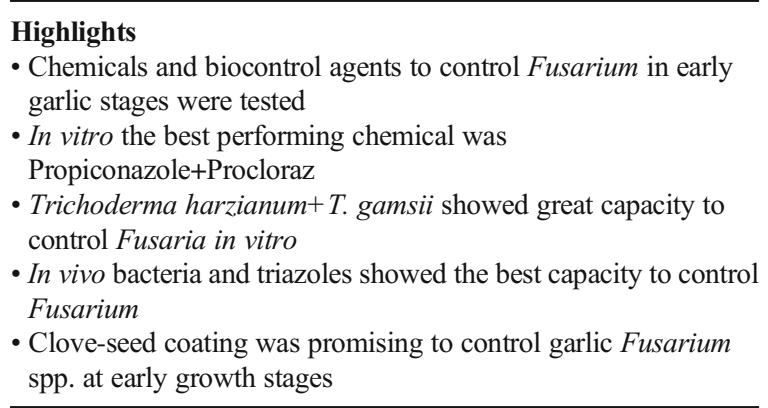

L. Mondani · G. Chiusa • P. Battilani $(\bowtie)$

Department of Sustainable Crop Production (DIPROVES),

Università Cattolica del Sacro Cuore, Via Emilia Parmense 84, 29122 Piacenza, Italy

e-mail: paola.battilani@unicatt.it control $F$. proliferatum and $F$. oxysporum compared to chemical products (mean of severity index $18.6 \%$ and $11.7 \%$, respectively). In vivo results confirmed the in vitro performances, except for Trichoderma, which had the worst performances in vivo. Therefore, the results are preliminary but promising for future field application.

\section{Keywords Allium sativum - Fusarium proliferatum .} Fusarium oxysporum - Seed coating · Biocontrol agent . Triazoles

\section{Introduction}

Garlic (Allium sativum L.) is cultivated worldwide in temperate regions and is used both for feed and for medical purposes. At a global level, 1.5 million hectares were occupied by this crop in 2018 and Italy was the sixth producer in Europe with 3573 ha (FAO-STAT 2018) characterized by high production values as PDO (Protected Designation of Origin) (Spagnoli 2014). In Piacenza province, an average of 328 tons of white garlic is produced annually, but up to $18 \%$ of the production is lost due to dry rot, an emerging disease, with local growers facing huge economic losses (COPAP, Cooperative of Piacenza garlic producers, personal communication). Worldwide, dry rot disease of garlic is a postharvest problem that results in the case of the most severe attacks of up to $30 \%$ of the garlic bulbs being completely emptied and softened. The disease symptoms are generally visible during the drying process of garlic bulbs as necrotic spots, centrally 
depressed, sometimes with white mycelium developed. With careful observation, they can also be detected during the growing season, mainly on roots and basal plates. Severe attacks, extending to bulbs, can lead to the death of garlic plants (Mondani et al. 2021). Fusarium proliferatum (T. Matsushima) Nirenberg is reported as the main causal agent of garlic dry rot. This fungus has been identified in the past few years as a garlic dry rot agent in Germany (Seefelder et al. 2002), North America (Dugan et al. 2003), Serbia (Stankovic et al. 2007), Spain (Palmero et al. 2010), Italy (Tonti et al. 2012), India (Sankar and Babu 2012), Egypt (Moharam et al. 2013; Elshahawy et al. 2017), Argentina (Salvalaggio and Ridao 2013), and France (Leyronas et al. 2018). Further, $F$. oxysporum has been reported as a causal agent of basal rot (Schwartz and Krishna Mohan 2016). In recent studies conducted in Piacenza province, $F$. proliferatum was reported in garlic bulbs from the crop's early growth stages, suggesting potential seed transmission as a source of this fungal pathogen, and it was the dominant fungus in infected bulbs postharvest, confirmed as the causal agent of dry rot (Mondani et al. 2020; Mondani et al. 2021).

Garlic is commonly propagated via cloves; therefore, the selection of healthy plant material is crucial to reduce pathogen dissemination. In a recent study, Dugan et al. observed that up to $77 \%$ of visibly healthy bulbs at harvest developed symptoms after 9-16 months storage, suggesting that cloves used as seeds, even if apparently healthy, can be infected by Fusaria (Dugan et al. 2019).

Garlic dry rot control is not established; only a few studies on the effectiveness of chemical and physical treatments against Fusarium spp. in garlic are available. Dugan et al. (2007) demonstrated the efficacy of Benomyl in eradicating Fusarium spp. from wounded bulbs, but this active ingredient is now banned in Europe. Elshahawy et al. (2017) reported that in in vitro assays, Carbendazim had a strong inhibition effect on fungal growth when followed by Metalaxyl + Mancozeb $(8 \%+64 \%)$ and thiophanate-methyl. Recently, Gálvez et al. (2017) investigated the ability of three commercial fungicides to control $F$. proliferatum in vitro with promising results, but field treatments failed to control garlic rot through the commercial stage. Physical methods, such as thermotherapy as a seed sanitization system, were also studied by Palmero Llamas et al. (2013), who demonstrated that thermotherapy at $50^{\circ} \mathrm{C}$ for one minute greatly decreases $F$. proliferatum conidia viability. However, this method should be carefully evaluated for its effect on clove germination. Finally, regarding BCAs, a few studies have reported their ability to control Fusarium spp. in vitro, but their application in garlic crop has not been tested yet (Evangelista-Martínez 2014; Ghanbarzadeh et al. 2014; Ju et al. 2014; Kavitha et al. 2013; Samsudin and Magan 2016). Trichoderma spp. and Bacillus subtilis seem to be the most promising active ingredients available commercially. Elshahawy et al. (2017) demonstrated the efficacy of Trichoderma spp. against $F$. proliferatum isolated from garlic in dual culture assays, while Bjelić et al. (2018) tested in vitro at $25^{\circ} \mathrm{C}$ for seven days the capacity of indigenous Serbian $B$. subtilis to limit the growth of Fusarium spp. isolated from garlic crops. In both cases, the results were promising, but no information is available regarding their efficacy.

As the disease was detected from early crop stages in field, sowing healthy cloves is crucial to grow healthy plants, but due to the high incidence of Fusarium spp. in soil and in symptomless cloves, it is vital to protect the plantlet during the early growth stages. Therefore, the aim of this study was to verify the efficacy of chemicals and biological fungicides towards $F$. proliferatum and F. oxysporum: i) grown in vitro on artificial media; ii) naturally occurring or artificially inoculated in cloves sown in pots, as possible seed coating treatments.

\section{Materials and methods}

Media

Water Agar (WA): $20 \mathrm{~g}$ of agar (2\%; Oxoid®, Basingstoke, UK), $1 \mathrm{~L}$ of bi-distilled water, amended with $250 \mathrm{ppm}$ of Streptomycin sulfate.

Potato Dextrose Agar (PDA): 15 g of agar (2\%; Oxoid®), $10 \mathrm{~g}$ of dextrose, $1 \mathrm{~L}$ of potato broth (200 $\mathrm{g}$ of potato/L of water).

Fungal strains

Fungal strains were selected to represent the main target fungus of garlic dry rot. One strain of $F$. oxysporum and two strains of $F$. proliferatum were included, isolated from garlic and maize - the crop of interest and that prevalent in the Po valley and frequently included in crop rotation, respectively. Two strains isolated from garlic cloves showing dry rot symptoms at field stages —one F. oxysporum ITEM18686 (FO) and one F. proliferatum ITEM18687 (FPg), confirmed by 
molecular identification (Mbofung and Pryor 2010; Nicolaisen et al. 2009), and one isolated from maize, $F$. proliferatum ITEM7595 (FPm), were included in the study. Strains are stored in the fungal collection of ISPA-CNR (Institute of Science of Food Production, National Research Centre; http://server.ispa.cnr. it/ITEM/Collection/). Five mm tassels were collected from the margin of five-day-old colonies, grown on WA incubated at $25{ }^{\circ} \mathrm{C}$, and used as inoculum.

In vitro test

\section{Chemicals}

Six commercial chemical fungicides were considered, all including triazoles, the active ingredients effective against Fusaria (Table 1). Before putting PDA into Petri dishes, fungicides were added in five different concentrations of the active ingredients: $0,1,10,100$, $1000 \mathrm{ppm}$.

Amended PDA was centrally inoculated with a $5 \mathrm{~mm}$ disc of each of the above-motioned strains (Gálvez et al. 2017).

\section{Biocontrol agents}

Four commercially available BCAs were selected based on their mode of action (Table 1); fungi are competitors, while bacteria and Actinomycetes produce antifungal compounds. The selected antagonists were tested in dual culture experiments.

Forty $\mu \mathrm{l}$ of cell suspension of Bacillus subtilis and Streptomyces griseoviridis (1 g of Serenade or Mycostop dissolved in $10 \mathrm{ml}$ of sterile potato broth, $200 \mathrm{~g}$ potato/L) were streaked in four lines on a half Petri dish containing PDA. After a five-day incubation at $25^{\circ} \mathrm{C}$, the $5 \mathrm{~mm}$ agar disc of the Fusaria strains was inoculated at a $20 \mathrm{~mm}$ distance on the other side of the dish (Sangdee et al. 2016). A $5 \mathrm{~mm}$ mycelial disc from the margin of a 7-day old colony of $F$. oxysporum and Trichoderma harzianum $+T$. gamsii and the Fusaria were inoculated on the opposite side of $90 \mathrm{~mm}$ Petri dishes with PDA (approximately $40 \mathrm{~mm}$ from each other).

\section{Growth reduction}

Both for chemicals and BCAs, control dishes were centrally inoculated with the FPg or FPm and FO (Gálvez Patón et al. 2017). All the plates were incubated at three different temperatures $\left(\mathrm{T} ;{ }^{\circ} \mathrm{C}\right): 10{ }^{\circ} \mathrm{C}$, $15{ }^{\circ} \mathrm{C}$, and $25^{\circ} \mathrm{C}$ with a $12 \mathrm{~h}$ photoperiod. The trials were managed with four replicates. The radial growth of the FPg, FPm and FO and the antagonist was measured after 21 days of incubation. The trials were repeated twice.

Table 1 Fungicides and biocontrol agents used for in vitro and in vivo trials aimed to reduce the growth of Fusarium proliferatum and $F$. oxysporum and the resulting disease severity on garlic; active ingredients dosage in commercial products and companies are reported

\begin{tabular}{lll}
\hline COMMERCIAL PRODUCT & ACTIVE INGREDIENT & COMPANY \\
\hline Chemicals & & \\
OPINION ECNA & Propiconazole $250 \mathrm{~g} / \mathrm{L}$ & ADAMA Italia, Grassobio, Italy \\
MYSTIC 430SC & Tebuconazole $250 \mathrm{~g} / \mathrm{L}$ & Nufarm Italia, Bologna, Italy \\
CUSTODIA & Tebuconazole $200 \mathrm{~g} / \mathrm{L}+$ Azoxystrobin $120 \mathrm{~g} / \mathrm{L}$ & ADAMA Italia, Grassobio, Italy \\
LUNA EXPERIENCE & Fluopyram $200 \mathrm{~g} / \mathrm{L}+$ Tebuconazole $200 \mathrm{~g} / \mathrm{L}$ & Bayer Crop Science, Milan, Italy \\
QUILT XCEL & Propiconazole $122.4 \mathrm{~g} / \mathrm{L}+$ Azoxystrobin $141.4 \mathrm{~g} / \mathrm{L}$ & Syngenta Italia, Milan, Italy \\
BUMPER P & Propiconazole $90 \mathrm{~g} / \mathrm{L}+$ Prochloraz $400 \mathrm{~g} / \mathrm{L}$ & ADAMA Italia, Grassobio, Italy \\
Biological & & \\
Serenade Max & Bacillus subtilis $\left(5.13 * 10^{10} \mathrm{UFC} / \mathrm{g}\right)$ & Bayer Crop Science, Milan, Italy \\
IF23 & Fusarium oxysporum $\mathrm{IF} 23\left(1 * 10^{7} \mathrm{UFC} / \mathrm{g}\right)$ & Xeda Italia, Forlì, Italy \\
Mycostop & Streptomyces griseoviridis K61 $\left(5^{*} 10^{8} \mathrm{UFC} / \mathrm{g}\right)$ & Verdera Oy, Kurjenkellontie, Finland \\
Remedier & Trichoderma harzianum + T. gamsii $\left(3 * 10^{7} \mathrm{UFC} / \mathrm{g}\right)$ & Isagro, Milan, Italy \\
\hline
\end{tabular}




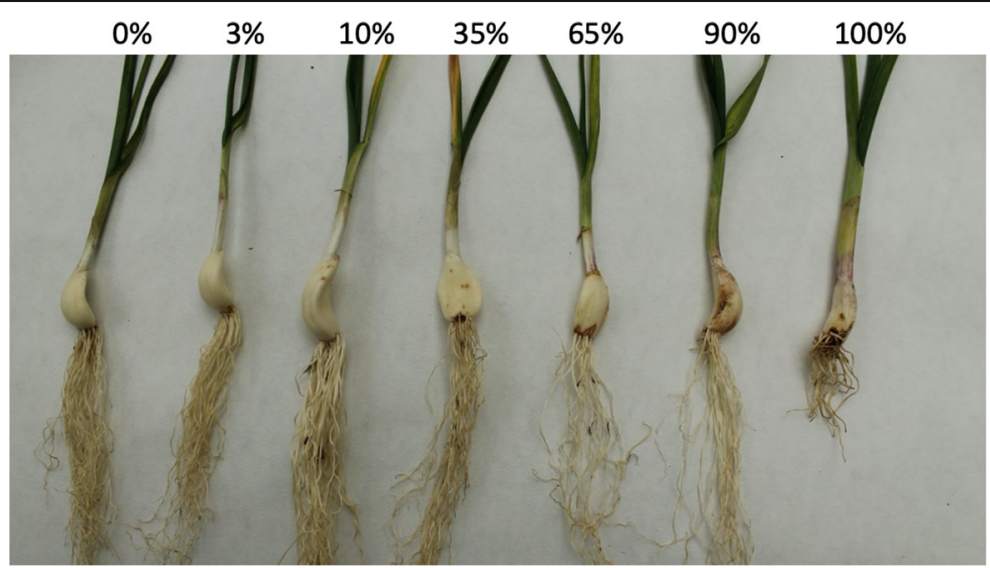

Fig. 1 Severity classes to assess disease severity caused by Fusarium oxysporum and Fusarium proliferatum in garlic. $0=$ asymptomatic; $3 \%=$ small lesions either on the bulb, the crown or the radicles; $10 \%=$ small lesions on two of the considered organs, $35 \%=$ small lesions on all the three organs considered;

At the end of the trials, the percentage of mycelial growth reduction (GR\%) was calculated using the formula:

$\mathrm{GR}(\%)=\mathrm{RC}-\mathrm{RA} / \mathrm{RC} \times 100$.

RC: colony radius (mm) of the control Fusarium strain.

RA: colony radius (mm) of the Fusarium strain in dual culture with the antagonist or in amended PDA.

\section{In vivo test}

Five active ingredients - two chemicals (Propiconazole + Prochloraz and Tebuconazole) and three BCAs (T. harzianum + T. gamsii, B. subtilis and $S$. griseoviridis)-were tested in in vivo trials. The choice was based on in vitro trial results.

Garlic cloves were sown in plastic pots $(14 \times 14 \times$ $16 \mathrm{~cm}$ ) containing sterile potting soil and pasteurized field clay soil (2:1). Before sowing, the cloves were washed for $20 \mathrm{~min}$ in running tap water, their surfaces disinfected for three minutes in $1 \% \mathrm{NaOCl}$ solution and rinsed in sterile distilled water three times. Then they were soaked for $15 \mathrm{~min}$ in the solutions of the abovementioned products and dried. Finally, the cloves were inoculated by dipping them in $10^{5}$ conidia/ml suspension of each of the three Fusaria strains. Each treatment consisted of eight cloves per pot, replicated four times. Active ingredients were paired with fungal strains so that each treatment was the combination of one active
$65 \%=$ extended lesions either on the bulb, the crown or the radicles; $90 \%=$ extended lesions on two of the considered organs; $100 \%=$ extended lesions on all the three organs considered with very limited root growth

ingredient and one fungal strain. All possible combinations were tested -60 pots in total. The untreated and uninoculated control was prepared by planting cloves without any previous treatment, either with FPg, FPm, and $\mathrm{FO}$ or with active ingredients (negative control). In addition, the inoculated control was made by dipping the cloves in conidial suspensions, but not treating them with active ingredients (positive control). The pots were placed in natural open conditions between October 2, 2018 and January 7, 2019. The experiment was arranged with a complete randomized block design. Meteorological data were collected daily using a data logger. The parameters measured were $\mathrm{T}\left({ }^{\circ} \mathrm{C}\right)$, relative humidity $(\mathrm{RH} ; \%)$, and rainfall $(\mathrm{R} ; \mathrm{mm})$.

At the end of the trial, plants were classified in seven severity classes of Fusarium symptoms (Fig. 10\%= asymptomatic; $3 \%=$ small lesions either on the bulb, the crown or the radicles; $10 \%=$ small lesions on two of the considered organs, $35 \%=$ small lesions on all the three organs considered; $65 \%=$ extended lesions either on the bulb, the crown or the radicles; $90 \%=$ extended lesions on two of the considered organs; $100 \%=\mathrm{ex}-$ tended lesions on all the three organs considered with very limited root growth), root length was measured, and isolation of Fusarium was managed on symptomatic plants. Portions of symptomatic tissues were surface sterilized for one minute in $\mathrm{NaOCl}$, rinsed three times in sterile water, dried in sterile conditions, and plated in Petri plates containing WA. Plates were incubated for seven days at $25^{\circ} \mathrm{C}$ with a 12 -h photoperiod. Emerging colonies were transferred to PDA for identification at 
microscope (Nikon, Eclipse 50, Japan, 500x), according to Leslie and Summerell (2006).

\section{Data analysis}

GR and severity data were arcsine transformed in order to homogenize variance (Clewer and Scarisbrick 2001), the analysis of variance (ANOVA) was applied and then Tukey's test was used to compare means, using the statistical package PASW statistics (ver.19, SPSS Inc., Chicago, USA, 2009).

\section{Results}

In vitro test

\section{Chemicals}

All factors investigated in the study, including fungal strains, active ingredients, their concentration, and incubation $\mathrm{T}$, as well as their interaction, significantly affected fungal growth $(P<0.01)$. No statistical differences were observed between repeated trials.

The fungal strains included in the study behaved differently depending on the chemicals applied. The efficacy in decreasing fungal growth was very good, between $88.6 \%$ and $81.3 \%$ GR impact detected on FPm and FO, respectively. Regarding the active ingredients, the mixture of Propiconazole + Prochloraz showed the greatest growth inhibition, around $100 \%$, followed by Tebuconazole (88.9\%), while Propiconazole, alone or in combination with Azoxystrobin, performed the worst. A significant decrease in efficacy in reducing fungal growth, from $99 \%$ to $63 \%$, was observed moving from the highest to the lowest active ingredient concentration. In addition, chemicals worked optimally at $10{ }^{\circ} \mathrm{C}$ and their efficacy decreased with $\mathrm{T}$ increase $(89.1 \% \mathrm{GR}$ at $10{ }^{\circ} \mathrm{C}$ versus $76.8 \%$ at $25^{\circ} \mathrm{C}$; Table 2). The interaction between the active ingredient and fungal strain tested was significant (Fig. 2). Propiconazole and Propiconazole + Azoxystrobin had the lowest impact on FO, while all the products containing Tebuconazole were more effective on FPm; the best performance on FPg, FPm, and FO was confirmed by Propiconazole + Prochloraz.

\section{Biocontrol agents}

In this study, BCA efficacy was significantly affected by the main factors, $\mathrm{T}$ and active ingredient $(P<0.01)$. No statistical differences were observed between repeated trials.

All the Fusarium strains showed a GR around 64\%. BCAs demonstrated varying capacity to reduce $F$. proliferatum and $F$. oxysporum growth; the most effective compound was based on $T$. harzianum $+T$. gamsii $(80.0 \%$ GR), followed by B. subtilis $(70.8 \%$ GR), $S$. griseoviridis (59.7\% GR), and $F$. oxysporum (47.7\% GR) (Table 3). Regarding T, the best BCA performance was observed at $15{ }^{\circ} \mathrm{C}$ with $68.2 \%$ GR, while the worst was at $25^{\circ} \mathrm{C}$, with $61.1 \%$ GR (Table 3, Fig. 3). However, the efficacy of $B$. subtilis suffers at the highest $\mathrm{T}\left(25^{\circ} \mathrm{C}\right)$, while $F$. oxysporum as BCA performed the worst at $10^{\circ} \mathrm{C}$ (Fig. 3).

Table 2 Analysis of variance of the percentage of growth reduction (GR\%) of three Fusarium spp. strains (one $F$. oxysporum isolated from garlic and two $F$. proliferatum, one of each isolated respectively from garlic and maize) grown on Potato Dextrose Agar added with six chemical products, incubated at three different temperatures $\left(\mathrm{T}=10-15-25^{\circ} \mathrm{C}\right)$ for 21 days

\begin{tabular}{|c|c|c|}
\hline Factors & GR\% & \\
\hline 1. Fungal strain & $* *$ & \\
\hline F. oxysporum ITEM18686 (FO) & 81.3 & $c$ \\
\hline F. proliferatum ITEM18687 (FPg) & 84.9 & $b$ \\
\hline F. proliferatum ITEM7595 (FPm) & 88.6 & $a$ \\
\hline 2. Active ingredient & $* *$ & \\
\hline Propiconazole & 76.4 & $d$ \\
\hline Propiconazole + Azoxystrobin & 73.2 & $e$ \\
\hline Propiconazole+Prochloraz & 99.9 & $a$ \\
\hline Tebuconazole & 88.9 & $b$ \\
\hline Tebuconazole + Azoxystrobin & 85.7 & $c$ \\
\hline Tebuconazole+Fluopyram & 85.7 & $c$ \\
\hline 3. Concentration & $* *$ & \\
\hline 1 & 62.8 & $d$ \\
\hline 10 & 84.0 & $c$ \\
\hline 100 & 93.7 & $b$ \\
\hline 1000 & 99.1 & $a$ \\
\hline 4. Temperature ${ }^{\circ} \mathrm{C}$ & $* *$ & \\
\hline 10 & 89.1 & $a$ \\
\hline 15 & 88.8 & $b$ \\
\hline 25 & 76.8 & $c$ \\
\hline
\end{tabular}


Fig. 2 Growth reduction (GR\%) of the three fungal strains, F. oxysporum ITEM18686(FO), $F$. proliferatum ITEM18687 (FPg) and $F$. proliferatum ITEM7595 (FPm), grown in vitro on spiked Potato Dextrose Agar medium with six commercial fungicides added (see Table 1 for details). $(P<0.05$. Standard error $=1.064)$

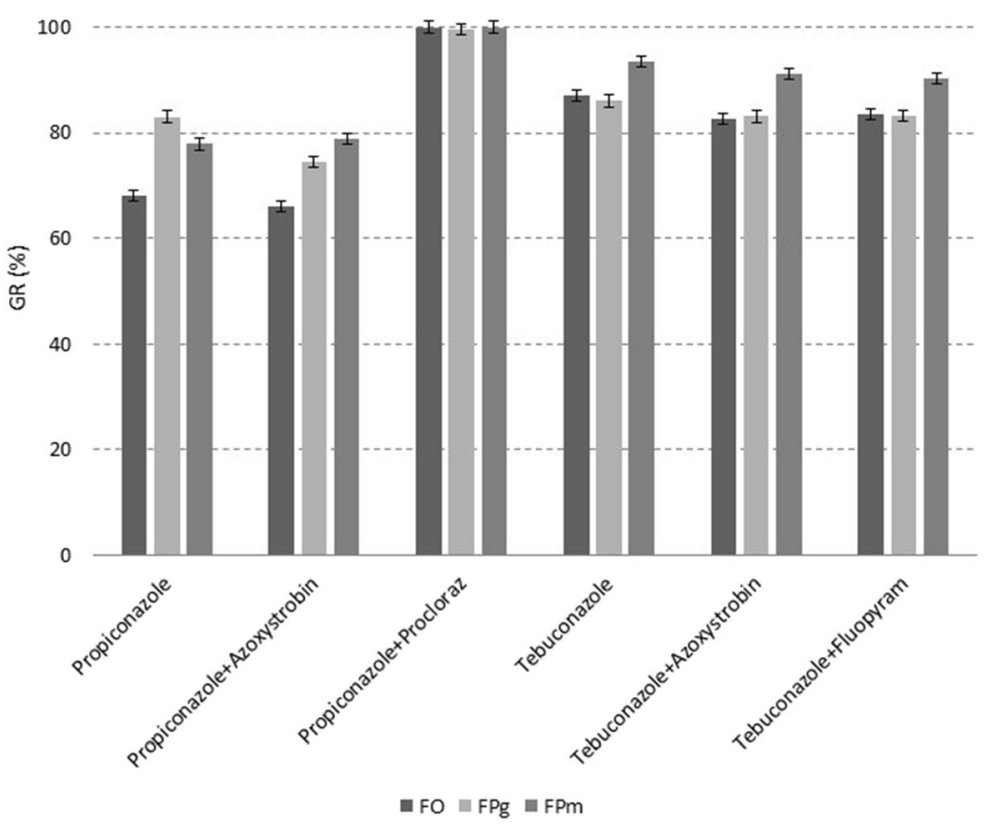

In vivo test

Garlic cloves sown in October and harvested in January were exposed to natural conditions similar to those occurring in normal garlic cultivation. The trial was stopped at the plant growth stage BBCH 14 (fourth leaf visible). Meteorological data collected during the trial are reported in Fig. 4. The minimum and maximum hourly $\mathrm{T}$ were respectively $-6.3{ }^{\circ} \mathrm{C}$ and $28.7{ }^{\circ} \mathrm{C}$. The calculated sum of degree-day was 884.1 and the mean $\mathrm{RH}$ was 87.3. The total $\mathrm{R}$ was $277 \mathrm{~mm}$ during the three months considered in the study.

Fungal strain and active ingredient applied had a significant impact $(P<0.01)$ on disease severity and root length, as did the interaction between the fungal strain and active ingredient. F. oxysporum and $F$. proliferatum were isolated from symptomatic plants inoculated, respectively, with those species; emerging colonies, cultured on PDA, were morphologically identical in color and shape to the original colonies used as inoculum source.

Cloves neither treated nor inoculated (negative control) showed a mean disease severity of $16.7 \%$ and mean radicle length of $23.3 \mathrm{~cm}$. Of the fungal strains, $\mathrm{FPg}$ produced the highest mean disease severity per plant (33.1\%), but plants had a similar radicle length with FO (mean $21.5 \mathrm{~cm}$ ). FPm caused the lowest disease severity $(18.1 \%)$, and the radicle reached the maximum length $(23.2 \mathrm{~cm})$. All the treatments applied significantly reduced disease severity compared to the inoculated control $(11.1 \%-24.8 \%$ versus $65.6 \%)$. Chemical products resulted in the lowest disease severity, $11.1 \%$ for Propiconazole + Prochloraz and $12.3 \%$ for Tebuconazole, significantly lower than T. harzianum +

Table 3 Analysis of variance of the percentage of growth inhibition (GR\%) of three Fusarium spp. strains (one F. oxysporum isolated from garlic and two $F$. proliferatum, one of each isolated respectively from garlic and maize) grown on Potato Dextrose Agar added with four different biocontrol agents, incubated at three different temperatures $\left(\mathrm{T}=10-15-25^{\circ} \mathrm{C}\right)$ for 21 days

\begin{tabular}{lrr}
\hline Factors & GR\% \\
\hline 1. Fungal strain & $n . s$. & \\
F. oxysporum ITEM18686 (FO) & 64.1 & \\
F. proliferatum ITEM18687 (FPg) & 64.9 & \\
F. proliferatum ITEM7595 (FPm) & 64.6 & \\
2. Active ingredient & $* *$ & \\
S. griseoviridis & 59.7 & $c$ \\
B. subtilis & 70.8 & $b$ \\
T. harzianum + T. gamsii & 80.0 & $a$ \\
F. oxysporum IF23 & 47.7 & $d$ \\
3. Temperature & $* *$ & \\
10 & 64.3 & $b$ \\
15 & 68.2 & $a$ \\
25 & 61.1 & $c$
\end{tabular}

n.s. = not significant; $* *(\mathrm{P}<0.01)$; Different letters indicate significant differences according to the Tukey test $(P<0.01)$ 
B. subtilis

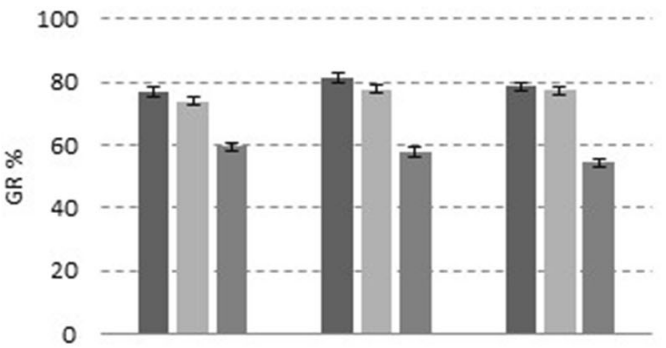

T. harzianum+T. gamsii

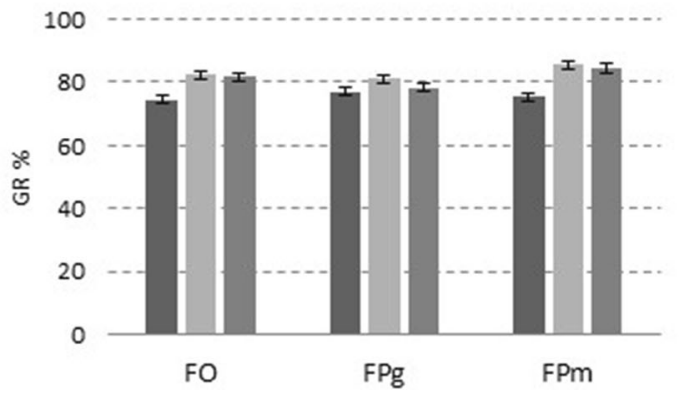

$\square 10^{\circ} \mathrm{C}$

Fig. 3 Growth reduction (GR\%) of the three fungal strains, $F$. oxysporum ITEM18686 (FO), F. proliferatum ITEM18687 (FPg) and F. proliferatum ITEM7595 (FPm), grown in Petri

T. gamsii (24.8\%). In terms of radicle length, the control registered the shortest radicles $(18.9 \mathrm{~cm})$ whereas the longest radicles were measured in plants treated with Tebuconazole $(+37 \%$; Table 4$)$.

The interaction between disease severity and the different treatments applied is shown in Fig. 5. Disease

\section{S. griseoviridis}

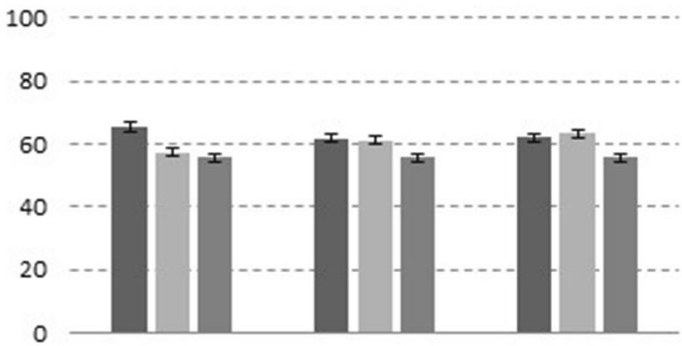

\section{F. oxysporum}

100

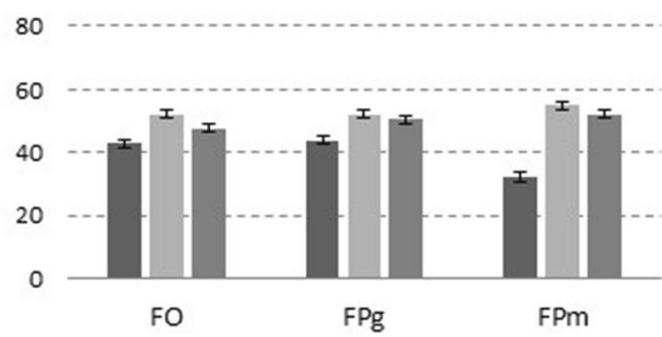

$15^{\circ} \mathrm{C}=25^{\circ} \mathrm{C}$

dishes on Potato Dextrose Agar with four biocontrol agents added (see Table 1 for details) in different temperature regimes. $(\mathrm{P}<$ 0.05. Standard error $=1.382$ )

severity of positive control was higher than all the treated cloves and BCAs were generally less effective in controlling FPg compared to FPm and FO. Also, chemical products showed differences in controlling FPg and FPm and FO, with Propiconazole + Prochloraz being more effective against isolates from garlic
Fig. 4 Meteorological data collected between October 2018 and January 2019 using a data logger placed close to the pots used for the in vivo trial included in this study. (Temperature ${ }^{\circ} \mathrm{C}$, relative humidity $\mathrm{RH}$ and millimeters of rain $\mathrm{mm}$ )

\section{Meteo Data}

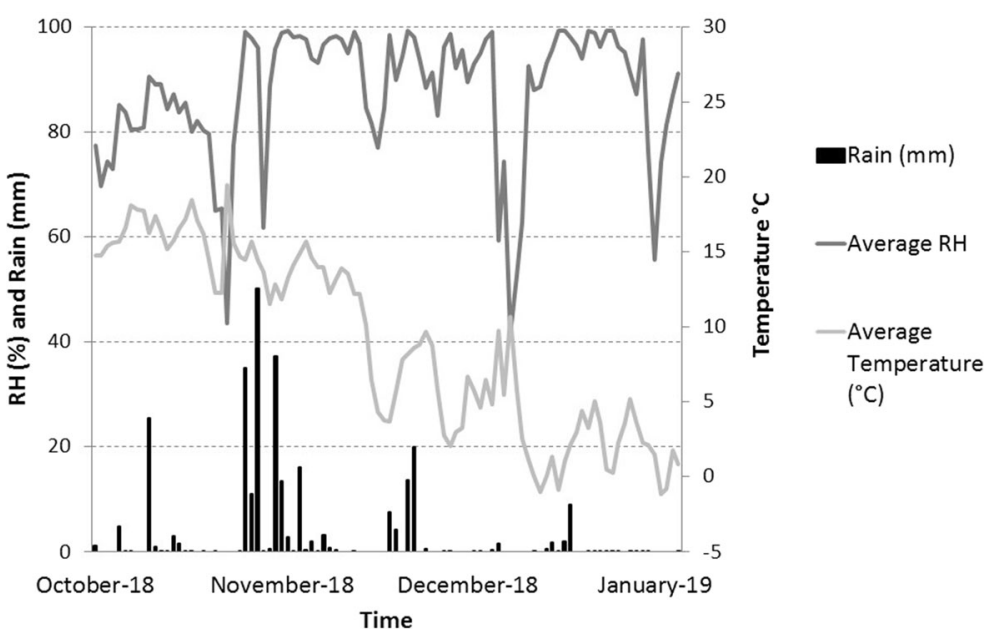


Table 4 Analysis of variance of disease severity (assessed according to the scale reported in Fig. 1) and radicle length of garlic plants grown in pots in open space from October 2, 2018 and January 7, 2019. Cloves were artificially inoculated before sowing by dipping in suspensions of five active ingredients, two chemicals (Propiconazole + Prochloraz and Tebuconazole) and three BCAs $(T$. harzianum $+T$. gamsii, B. subtilis, $S$. griseoviridis) and then in the conidial suspensions of three Fusarium spp. strains (one $F$. oxysporum isolated from garlic and two $F$. proliferatum, one of each isolated respectively from garlic and maize)

\begin{tabular}{|c|c|c|c|c|}
\hline Factors & Severity & & $\begin{array}{l}\text { Radicle } \\
\text { Length }(\mathrm{cm})\end{array}$ & \\
\hline 1. Strain & $* *$ & & $*$ & \\
\hline F. oxysporum ITEM18686 (FO) & 24.2 & $b$ & 21.5 & $b$ \\
\hline F. proliferatum ITEM18687 (FPg) & 18.1 & $a$ & 22.3 & $a b$ \\
\hline F. proliferatum ITEM7595 (FPm) & 33.1 & $c$ & 23.2 & $a$ \\
\hline 2. Treatment & $* *$ & & $* *$ & \\
\hline Positive Control a & 65.6 & $a$ & 18.9 & $d$ \\
\hline Propiconazole+Prochloraz & 11.1 & $c$ & 21.1 & $c$ \\
\hline Tebuconazole & 12.3 & $c$ & 25.9 & $a$ \\
\hline S. griseoviridis & 20.1 & $b c$ & 22.3 & $b c$ \\
\hline B. subtilis & 17.0 & $b c$ & 23.6 & $b$ \\
\hline T. harzianum+T. gamsii & 24.8 & $b$ & 22.3 & $b c$ \\
\hline
\end{tabular}

${ }^{\mathrm{a}}$ Positive control = cloves artificially inoculated with Fusarium spp., no fungicide application

** $(\mathrm{P}<0.01), *(\mathrm{P}<0.05)$; Different letters indicate significant differences according to the Tukey test

compared to FPm isolated from maize (11.3-10.2\% disease severity versus $11.8 \%$ ). Radicle length was greatly affected by the interaction between the Fusarium strain-inoculated cloves and those treated with fungicide. The radicles were shorter in cloves inoculated with FO, except when treated with Tebuconazole, whereas they were the longest when the cloves were inoculated with FPm, irrespective of the fungicide applied.

\section{Discussion}

Garlic dry rot is mainly reported in literature as a postharvest disease, but garlic infection starts in the field, and the first growth stages of the crop are crucial (Mondani et al. 2020; Mondani et al. 2021; Palmero et al. 2012; Stankovic et al. 2007). We also observed that apparently healthy cloves used in this study as negative control (neither treated nor inoculated) can develop symptoms during the early stages of garlic growth. This confirms the natural occurrence of Fusaria inoculum in visibly healthy cloves and the relevance of finding out effective seed treatments. Therefore, scoring the efficacy of seed treatment with fungicides as a preventive action against garlic dry rot in the first stages of crop growing was the aim of this study.

Triazoles are known for their capacity to reduce Fusaria growth, with LD 50 ranging from 0.24 to $6.5 \mathrm{mg} / \mathrm{L}$ and LD 90 of $10 \mathrm{mg} / \mathrm{L}$ (Marín et al. 2013; Müllenborn et al. 2008), by inhibiting the demethylation step in sterol biosynthesis in the cell membrane (Osborne and Scott 2018). They were considered in this study, aimed at controlling $F$. proliferatum and $F$. oxysporum, the former mentioned as the main causal agent of garlic rot and the latter also reported by some authors as involved in the disease (Gálvez Patón et al. 2017; Matuo et al. 1986; Tonti et al. 2012). BCAs were also selected in order to test the widest range of mechanisms of action against pathogens, so as to minimize the impact on the environment.

B. subtilis produces active compounds that inhibit plant pathogen growth and stimulate systemic responses in crops (Stein 2005) and has shown the capacity to reduce mycelial growth and sporulation in $F$. graminearum and F. oxysporum (Kim and Knudsen 2013; Zhao et al. 2014). $S$. griseoviridis stimulates plant systemic response, but it is also able to produce antibiotics and hydrolytic enzymes that attack cell membranes, as shown for $F$. oxysporum and $F$. proliferatum isolated from cucurbit plants (Zhao et al. 2013). Finally, fungal BCAs, Trichoderma spp. and F. oxysporum, compete for space and nutrients and can parasitize the pathogens (Kubicek et al. 2001). For example, Postma and Rattink (1992) were able to isolate nonpathogenic $F$. oxysporum, inoculated in the soil, in carnation stems up to $60 \mathrm{~cm}$, while on the other hand Trichoderma spp. showed a capacity to parasitize isolates of $F$. oxysporum even $48 \mathrm{~h}$ after the inoculation in dual culture (Sharma 2011).

In this study, triazoles, in both in vitro and in vivo trials, showed the best performances in reducing Fusaria growth when compared to other chemicals or biological control agents. Tebuconazole was more effective than Propiconazole (GR $88.9 \%$ versus $76.4 \%$ ), but the formulation Propiconazole + Prochloraz reduced the growth of Fusaria in vitro up to $100 \%$. A relevant role was apparently played by Prochloraz; in fact, all the other products containing Triazoles in a mixture with other active ingredients, Prochloraz excluded, were less effective compared to active ingredient applied alone. Further, Ivic et al. (2011) applied Prochloraz in in vitro 
Fig. 5 Disease severity and radicle length $(\mathrm{cm})$ of the three fungal strains, $F$. oxysporum ITEM18686 (FO),

$F$. proliferatum ITEM18687

$(\mathrm{FPg})$ and $F$. proliferatum

ITEM7595 (FPm), tested in in vivo trial with six seed coating treatments. (Standard error disease severity $=1.791$. Standard error radicle length $=0.511$ )

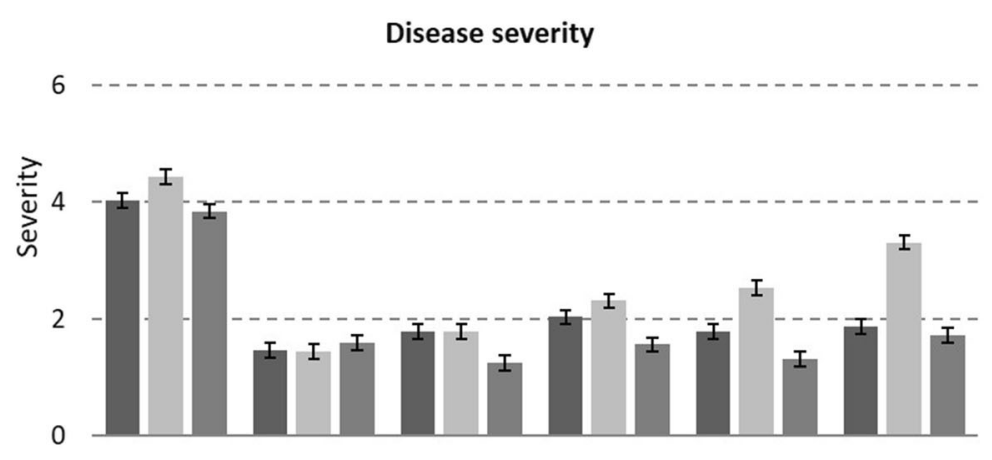

Radicle length

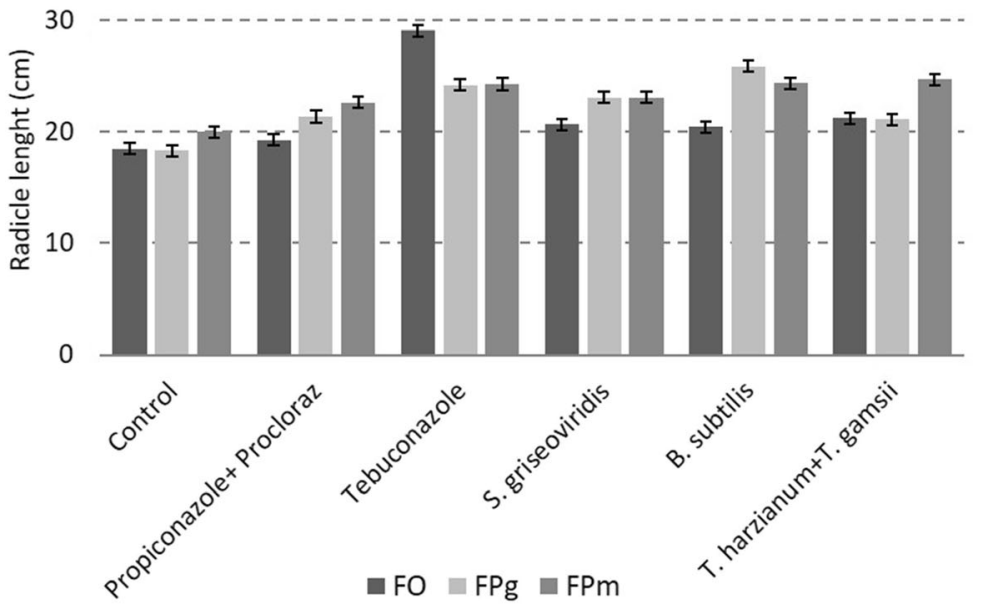

studies, and $F$. verticilloides growth inhibition was up to $96 \%$.

Azoxystrobin was reported to be almost ineffective in inhibiting Fusarium growth in vitro (Müllenborn et al. 2008). The results collected in this in vitro trial confirm this statement; in fact, the mixture of Propiconazole and Azoxystrobin showed the worst performance in inhibiting Fusaria growth among the chemicals tested. The reduced efficacy of products containing Azoxystrobin applied to the cloves could be explained by its translaminar mobility, compared to other compounds, systemically moving in the plant (Ravichandra 2018).

The results obtained in vitro with BCAs are in accordance with literature reports (Elshahawy et al. 2017; Bjelić et al. 2018). A mean growth inhibition of $80 \%$ for T. harzianum $+T$. gamsii and $70 \%$ for $B$. subtilis is very promising, especially if we consider their thermal needs; in fact, those microorganisms can successfully overwinter and continue their action in the later stages of crop growth.

A step forward was achieved by sowing cloves, treated with the most promising fungicides, in pots in the open air. The chemicals performed better in terms of reduction of disease severity compared to BCAs $(11.7 \%$ versus $18.6 \%$ disease severity, respectively with chemical and biological control), but Propiconazole + Prochloraz showed a side effect on radicle lengths, shorter compared to those measured in plants treated with the other chemical products (mean $21 \mathrm{~cm}$ versus mean $26 \mathrm{~cm}$, with Propiconazole + Prochloraz and Tebuconazole respectively). Plants with a weak radical apparatus normally are more susceptible to diseases (Fageria 2012); therefore, this could be relevant in the field where the growing season is much longer than in this trial, around 270 versus 90 days, respectively.

BCAs involved in this study showed a similar capacity to control $F$. proliferatum in terms of the severity of symptoms on cloves, and they did not show negative effects on radicle length. B. subtilis and S. griseoviridis performances were comparable to those observed for chemicals, in terms of reduced disease severity, with mean values of $74 \%$ and $69 \%$ respectively. In vivo results seem in contrast with those obtained in vitro for 
T. harzianum $+T$. gamsii: Fusaria growth was reduced by up to $85 \%$ in vitro, the best performance of the BCAs, but only $62 \%$ in pot trials, with final disease severity scored at $24.8 \%$. During the pot experiment, $\mathrm{T}$ was below $10{ }^{\circ} \mathrm{C}$ for a long period and T. harzianum + T. gamsii showed the worst performance with this $\mathrm{T}$ in in vitro studies; this can justify the loss of performance. In addition, artificial culture media such as PDA are rich in sugar and nutrients, which are easily consumed by Trichoderma species; on the other hand, soil contained in pots was poorer in nutrients and organic matter, not giving BCAs a competitive advantage over the pathogen (Klein and Eveleigh 1998).

During the early stages of garlic development, water supply and mild $\mathrm{T}$ are required for rapid clove germination, but these conditions are also conducive for Fusaria. During our pot trial, $\mathrm{T}$ was higher than $10{ }^{\circ} \mathrm{C}$ until midNovember and a water supply was guaranteed by periodic rainfall. The rainiest period was between mid-October and the beginning of November, when the plants showed 3-4 visible leaves (BBCH13-BBCH14) and $\mathrm{T}$ was around $15^{\circ} \mathrm{C}$. In vitro, BCAs were more effective against Fusarium at $15^{\circ} \mathrm{C}$ than at $10^{\circ} \mathrm{C}$ and $25^{\circ} \mathrm{C}$; all the antagonistic species used in the study are known as mesophilic. Trichoderma has its optimum growth with $\mathrm{T}$ between 25 and $30{ }^{\circ} \mathrm{C}$ (Klein and Eveleigh 1998) and at $5-10{ }^{\circ} \mathrm{C}$, its growth and secondary metabolite activity is reduced (Tronsmo and Dennis 1978). Bacterial BCAs showed a capacity to grow and multiply at a $\mathrm{T}$ of $4{ }^{\circ} \mathrm{C}$ (Berzina et al. 2016; Isnawati and Trimulyono 2018). The rapidity of bacterial cells to reproduce in favorable conditions could explain their effectiveness against Fusarium in the early stages of plant growth when $\mathrm{T}$ are around $10-15^{\circ} \mathrm{C}$. On the other hand, Trichoderma species are more sensible to low $\mathrm{T}$ and their activity is reduced in the early crop stages (Tronsmo and Dennis 1978).

In the present study, all the Fusaria strains caused symptoms on garlic seedlings, but FPg showed the highest severity index in in vivo trials, with symptoms on bulbs, supporting $F$. proliferatum as the main causal agent of dry rot in garlic in Europe (Stankovic et al. 2007; Palmero et al. 2010; Tonti et al. 2012; Mondani et al. 2020; Mondani et al. 2021). However, FPm, which was originally isolated from maize, was capable of infecting garlic plants, scoring a severity index of $18.1 \%$ versus $33.1 \%$, confirming the non-host specificity of Fusaria, but also a certain adaptation to the crop (Proctor et al. 2010). Palmero et al. (2012) also demonstrated the capability of $F$. proliferatum strains isolated from garlic to cause disease in other Liliaceae. Onion registered the highest disease severity, followed by garlic, leek, chives, and scallion in artificial inoculation trials conducted by dipping the seedlings in conidial suspension before planting them in pots. This observation is highly relevant in the perspective of defining the best crop rotation and minimizing Fusaria inoculum in field soil.

\section{Conclusions}

Both BCAs and chemicals showed the capacity to greatly reduce Fusarium spp. growth in in vitro trials and the results were confirmed, even with reduced impact, in in vivo experiments. Moreover, the study demonstrated the efficacy of coating products in reducing Fusarium symptom severity in the early crop stages. As dry rot is mainly a matter of concern postharvest, it will be of great interest to investigate whether the effectiveness of these treatments lasts long enough to protect garlic until storage and market stage. This is a preliminary study, but it is mandatory to select the most promising active ingredients for garlic dry rot control. Further studies are ongoing to check the efficacy of fungicides used for seed coating during garlic cultivation and storage; if promising results are confirmed, they will hopefully contribute to support farmers in the management of garlic dry rot.

Acknowledgments The research was funded by the PSR program "16.1.01 Gruppi operativi del PEI per la produttività e le sostenibilità dell'agricoltura" Sottomisura 16.1 of EmiliaRomagna region, Focus Area 2A. Project "Guidelines to counteract Fusarium rot in Piacenza White Garlic." Letizia Mondani worked on this project as a $\mathrm{PhD}$ student in the Agrisystem program at doctoral school, funded by the mentioned project.

Availability of data and material Data will be available on request.

Code availability Not applicable.

Authors' contributions All authors contributed to the study conception and design. Material preparation, data collection, and analysis were performed by all authors. All authors read and approved the final manuscript.

Funding Open access funding provided by Università Cattolica del Sacro Cuore within the CRUI-CARE Agreement. This research did not receive any specific grant from funding agencies in the public, commercial, or not-for-profit sectors. 


\section{Declarations}

Ethics approval Not applicable, no humans or animals were used in this research.

\section{Consent to participate Not applicable.}

Consent for publication Not applicable.

Conflicts of interest/competing interests The authors declare that they have no known competing financial interests or personal relationships that could have appeared to influence the work reported in this paper.

Open Access This article is licensed under a Creative Commons Attribution 4.0 International License, which permits use, sharing, adaptation, distribution and reproduction in any medium or format, as long as you give appropriate credit to the original author(s) and the source, provide a link to the Creative Commons licence, and indicate if changes were made. The images or other third party material in this article are included in the article's Creative Commons licence, unless indicated otherwise in a credit line to the material. If material is not included in the article's Creative Commons licence and your intended use is not permitted by statutory regulation or exceeds the permitted use, you will need to obtain permission directly from the copyright holder. To view a copy of this licence, visit http://creativecommons.org/licenses/by/4.0/.

\section{References}

Berzina, A., Nikolajeva, V., \& Petrina, Z. (2016). Immobilization and survival of plant growth-promoting Bacteria Streptomyces griseoviridis and Azotobacter sp. Journal of Materials and Environmental Science, 7(9), 3381-3386.

Bjelić, D., Ignjatov, M., Marinković, J., Milošević, D., Nikolić, Z., Gvozdanović-Varga, J., \& Karaman, M. (2018). Bacillus isolates as potential biocontrol agents of Fusarium clove rot of garlic. Zemdirbyste-Agriculture, 105(4), 369-376. https://doi.org/10.13080/z-a.2018.105.047.

Dugan, F. M., Hellier, B. C., \& Lupien, S. L. (2003). First report of Fusarium proliferatum causing rot of garlic bulbs in North America. Plant Pathology, 52(3), 426. https://doi. org/10.1046/j.1365-3059.2003.00852.x.

Clewer, A. G., \& Scarisbrick, D. H. (2001). Practical Statistics and Experimental Design for Plant andCrop Science ( $\mathrm{p}$. 332). England: John Wiley \& Sons, Ltd.

Dugan, F. M., Hellier, B. C., \& Lupien, S. L. (2007). Pathogenic fungi in garlic seed cloves from the United States and China, and efficacy of fungicides against pathogens in garlic germplasm in Washington state. Journal of Phytopathology, 155, 437-445. https://doi.org/10.1111/j.1439-0434.2007.01255.x.

Dugan, F. M., Lupien, S. L., \& Hellier, B. C. (2019). Infection by Fusarium proliferatum in aerial garlic bulbils is strongly reduced compared to rates in seed cloves when both originate from infected bulbs. Crop Protection, 116, 43-48. https://doi. org/10.1016/j.cropro.2018.10.006.

Elshahawy, I. E., Saied, N. M., Morsy, A. A., \& Saied, N. M. (2017). Fusarium proliferatum, the main cause of clove rot during storage, reduce clove germination and causes wilt of established garlic plants. Journal of Plant Pathology, 99(1), 85-93. https://doi.org/10.4454/jpp.v99i1.3794.

Evangelista-Martínez, Z. (2014). Isolation and characterization of soil Streptomyces species as potential biological control agents against fungal plant pathogens. World Journal of Microbiology and Technology, 30, 1639-1647. https://doi. org/10.1007/s1 1274-013-1568-x.

Fageria, N. K. (2012). The role of plant roots in crop production. https://doi.org/10.1201/b12365.

FAO-STAT. (2018). FAO-STAT. http://www.fao. org/faostat/en/\#home

Gálvez, L., Urbaniak, M., Waśkiewicz, A., Stępień, Ł., \& Palmero, D. (2017). Fusarium proliferatum - Causal agent of garlic bulb rot in Spain: Genetic variability and mycotoxin production. Food Microbiology, 67, 41-48. https://doi. org/10.1016/j.fm.2017.05.006.

Gálvez Patón, L., Redondas Marrero, M. D., \& Palmero Llamas, D. (2017). In vitro and field efficacy of three fungicides against Fusarium bulb rot of garlic. European Journal of Plant Pathology, 148(2), 321-328. https://doi.org/10.1007 /s10658-016-1091-7.

Ghanbarzadeh, B., Safaie, N., \& Goltapeh, E. M. (2014). Antagonistic activity and hyphal interactions of Trichoderma spp. against Fusarium proliferatum and F. oxysporum in vitro. Archives of Phytopathology and Plant Protection, 47(16), 1979-1987. https://doi. org/10.1080/03235408.2013.864506.

Isnawati, \& Trimulyono, G. (2018). Temperature range and degree of acidity growth of isolate of indigenous bacteria on fermented feed "fermege.". Journal of Physics: Conference Series, 953, 12209. https://doi.org/10.1088/1742-6596/953/1/012209.

Ivic, D., Sever, Z., \& Kuzmanovska, B. (2011). In vitro sensitivity of Fusarium graminearum, $F$. avenaceum and $F$. verticillioides to carbendazim, tebuconazole, flutriafol, metconazole and prochloraz. Pesticidi i fitomedicina, 26(1), 35-42. https://doi.org/10.2298/pif1 101035i.

Ju, R., Zhao, Y., Li, J., Jiang, H., Liu, P., Yang, T., Bao, Z., Zhou, B., Zhou, X., \& Liu, X. (2014). Identification and evaluation of a potential biocontrol agent, Bacillus subtilis, against Fusarium spp. in apple seedlings. Annuals of Microbiology, 64, 377-383.

Kavitha, T., Nelson, R., Kavitha, T., \& N. R. (2013). Exploiting the biocontrol activity of Trichoderma spp. against root rot causing phytopathogens. ARPN Journal of Agricultural and Biological Science, 8(7), 571-574 ISSN 1990-6145.

Kim, T. G., \& Knudsen, G. R. (2013). Relationship between the biocontrol fungus Trichoderma harzianum and the phytopathogenic fungus Fusarium solani f.sp. pisi. Applied Soil Ecology, 68, 57-60. https://doi.org/10.1016/j.apsoil.2013.03.009.

Klein, D., \& Eveleigh, E. (1998). Ecology of Trichoderma. Trichoderma and Gliocladium, 1.

Kubicek, C. P., Mach, R. L., Peterbauer, C. K., \& Lorito, M. (2001). Trichoderma: From genes to biocontrol. Journal of Plant Pathology, 83, 11-23. http://www.jstor. org/stable/41998018 
Leyronas, C., Chrétien, P. L., Troulet, C., Duffaud, M., Villeneuve, F., Morris, C. E., \& Hunyadi, H. (2018). First report of Fusarium proliferatum causing garlic clove rot in France. Plant Disease, 102(12), 2658. https://doi. org/10.1094/PDIS-06-18-0962-PDN.

Leslie, J. F., \& Summerell, B. A. (2006). The Fusarium laboratory manual (pp. 1-2). Hoboken: Blackwell Publishing. https://doi.org/10.1002/9780470278376.

Marín, P., de Ory, A., Cruz, A., Magan, N., \& González-Jaén, M. T. (2013). Potential effects of environmental conditions on the efficiency of the antifungal tebuconazole controlling Fusarium verticillioides and Fusarium proliferatum growth rate and fumonisin biosynthesis. International Journal of Food Microbiology, 165(3), 251-258. https://doi. org/10.1016/j.ijfoodmicro.2013.05.022.

Matuo, T., Miyagawa, M., \& Saito, H. (1986). Fusarium oxysporum $f \cdot s p \cdot$ garlic n. f.sp. causing basal rot of garlic. Annals of Phytopathological Society Japan, 52, 860-864.

Mbofung, G. C. Y., \& Pryor, B. M. (2010). A PCR-based assay for detection of Fusarium oxysporum $f$. sp. lactucae in lettuce seed. Plant Disease, 94(7), 860-866. https://doi.org/10.1094/ PDIS-94-7-0860.

Moharam, M. H. A., Farrag, E. S. H., \& Mohamed, M. D. A. (2013). Pathogenic fungi in garlic seed cloves and first report of Fusarium proliferatum causing cloves rot of stored bulbs in upper Egypt. Archives of Phytopathology and Plant Protection, 46(17), 2096-2103. https://doi.org/10.1080 /03235408.2013.785122.

Mondani, L., Chiusa, G., Pietri, A., \& Battilani, P. (2020). Monitoring the incidence of dry rot caused by Fusarium proliferatum in garlic at harvest and during storage. Postharvest Biology and Technology., 173, 111407. https://doi.org/10.1016/j.postharvbio.2020.111407.

Mondani, L., Chiusa, G., Battilani, P. (2021). Fungi associated with garlic during the cropping season, with focus on Fusarium proliferatum and $F$. oxysporum. Plant health progress. https://doi.org/10.1094/PHP-06-20-0054-RS.

Müllenborn, C., Steiner, U., Ludwig, M., \& Oerke, E.-C. C. (2008). Effect of fungicides on the complex of Fusarium species and saprophytic fungi colonizing wheat kernels. European journal of plant pathology (Vol. 120). Dordrecht: Springer Netherlands. https://doi.org/10.1007/s10658-007-9204-y.

Nicolaisen, M., Suproniene, S., Nielsen, L. K., Lazzaro, I., Spliid, N. H., Justesen, A. F., et al. (2009). Real-time PCR for quantification of eleven individual Fusarium species in cereals. Journal of Microbiological Methods, 76(3), 234-240. https://doi.org/10.1016/j.mimet.2008.10.016.

Osborne, R., \& Scott, M. (2018). Frac code list 2018.

Palmero, D., De Cara, M., Iglesias, C., Moreno, M. M., González, N., Tello, J. C., et al. (2010). First report of Fusarium proliferatum causing rot of garlic bulbs in Spain. Plant Disease, 94(2), 277. https://doi.org/10.1094/PDIS-94-2-0277C.

Palmero, D., De Cara, M., Nosir, W., Gàlvez, L., Cruz, A., Woodward, S., et al. (2012). Fusarium proliferatum isolated from garlic in Spain: Identification, toxigenic potential and pathogenicity on related Allium species. Phytopathologia Mediterranea, 51(1), 207-218. https://doi.org/10.14601 /Phytopathol_Mediterr-10341.

Palmero Llamas, D., Gàlvez Patón, L., García Díaz, M., Gil Serna, J., \& Benito Sáez, S. (2013). The effects of storage duration, temperature and cultivar on the severity of garlic clove rot caused by Fusarium proliferatum. Postharvest Biology and Technology, 78, 34-39. https://doi.org/10.1016/j. postharvbio.2012.12.003.

Postma, J., \& Rattink, H. (1992). Biological control of Fusarium wilt of carnation with a nonpathogenic isolate of Fusarium oxysporum. Canadian Journal of Botany, 70(6), 1199-1205. doi.org/10.1139/b92-150.

Proctor, R. H., Desjardins, A. E., Moretti, A., Gullino, R. N., \& Strange, M. L. (2010). Biological and chemical complexity of Fusarium proliferatum. In The Role of Plant Pathology in Food Safety and Food Security (pp. 97-111). https://doi. org/10.1007/978-1-4020-8932-9_9.

Ravichandra, N. G. (2018). Agrochemicals in plant disease management. Scientific Publishers. https://books.google. it/books?id=PRiUDwAAQBAJ

Salvalaggio, A. E., \& Ridao, A. (2013). Disease notes first report of Fusarium proliferatum causing rot on garlic and onion in Argentina. Plant Disease, 97(4), 556. https://doi.org/10.1094 /PDIS-05-12-0507-PDN.

Samsudin, N. I. P., \& Magan, N. (2016). Efficacy of potential biocontrol agents for control of Fusarium verticillioides and Fumonisin B1 under different environmental conditions. World Mycotoxin Journal, 9(2), 205-213.

Sangdee, A., Kornphachara, S., \& Srisawat, N. (2016). In vitro screening of antagonistic activity of soil Streptomyces against plant pathogenic fungi and assessment of its characters. Journal of Agricultural Technology, 12(1), 173-185.

Sankar, N. R., \& Babu, G. P. (2012). First report of Fusarium proliferatum causing rot of garlic bulbs (Allium sativum) in India. Plant Disease, 96(2), 649. https://doi.org/10.1094 /PDIS-08-11-0649.

Schwartz, Howard F, and Krishna Mohan, S. 2016. "PART I: Infectious/biotic diseases." In Compendium of Onion and Garlic Diseases and Pests, Second Edition, edited by Howard F Schwartz and S Krishna Mohan, 8-86. Diseases and Pests Compendium Series. Scientific Societies. https://doi.org/10.1094/9780890545003.002.

Seefelder, W., Gossmann, M., \& Humpf, H.-U. (2002). Analysis of Fumonisin B1 in Fusarium proliferatum-infected Asparagus spears and garlic bulbs from Germany by liquid chromatography-electrospray ionization mass spectrometry. Journal of Agricultural and Food Chemistry, 50(10), 27782781. https://doi.org/10.1021/jf0115037.

Sharma, P. (2011). Complexity of Trichoderma-Fusarium interaction and manifestation of biological control. Australian Journal of Crop Science, 5(8), 1027-1038.

Spagnoli, S. (2014). La qualità carta vincente contro l'import a basso prezzo. Agricoltura, 36-37.

Stankovic, S., Levic, J., Petrovic, T., Logrieco, A., \& Moretti, A. (2007). Pathogenicity and mycotoxin production by Fusarium proliferatum isolated from onion and garlic in Serbia. European Journal of Plant Pathology, 118(2), 165172. https://doi.org/10.1007/s10658-007-9126-8.

Stein, T. (2005). Bacillus subtilis antibiotics: Structures, syntheses and specific functions. Molecular Microbiology, 56(4), 845857. https://doi.org/10.1111/j.1365-2958.2005.04587.x.

Tonti, S., Prà, M. D., Nipoti, P., Prodi, A., \& Alberti, I. (2012). First report of Fusarium proliferatum causing rot of stored garlic bulbs (Allium sativum L.) in Italy. Journal of Phytopathology, 160(11-12), 761-763. https://doi. org/10.1111/jph.12018. 
Tronsmo, A., \& Dennis, C. (1978). Effect of temperature on antagonistic properties of Trichoderma species. Transactions of the British Mycological Society, 71(3), 469-474. https://doi.org/10.1016/S0007-1536(78)80075-8.

Zhao, J., Xue, Q., Niu, G., Xue, L., Shen, G., \& Du, J. (2013). Extracellular enzyme production and fungal mycelia degradation of antagonistic Streptomyces induced by fungal mycelia preparation of cucurbit plant pathogens. Annals of
Microbiology, 63(2), 809-812. https://doi.org/10.1007 /s13213-012-0507-7.

Zhao, Y., Selvaraj, J. N., Xing, F., Zhou, L., Wang, Y., Song, H., Tan, X., Sun, L., Sangare, L., Folly, Y. M. E., \& Liu, Y. (2014). Antagonistic action of Bacillus subtilis strain SG6 on Fusarium graminearum. PLoS One, 9(3), e92486. https://doi.org/10.1371/journal.pone.0092486. 